Available online at:
http://www. ulead.org.tr/journal
International Association of Research

\title{
The Sociolinguistics of Sign Languages
}

\author{
(Edited by Ceil Lucas, Cambridge University Press, 2004, Cambridge, UK)
}

\author{
Ebru Altın ${ }^{1}$ \\ Çanakkale Onsekiz Mart University, Turkey
}

The Sociolinguistics of Sign Languages is a study published by Cambridge University Press in 2004 and edited by Ceil Lucas who has been teaching a graduate level course entitled Sociolinguistics in Deaf Communities at Gallaudet University in Washington, DC since 1980s. When he first started his teaching, there were readings from 1960s and 1970s; however, new studies have been required with the growing importance of sign language community's needs and empowerment. In the introduction part Lucas states the history of sign language studies, today's situations and his reflections on the importance of the sociolinguistic research for Deaf communities. In the book, there are six main areas to examine which are multilingualism, bilingualism, sociolinguistic variation, discourse analysis, language planning and policy and language attitudes.

The first topic which Woll, Sutto-Spence and Elton deal with is Multilingualism. In this chapter, the global approach to sign languages is discussed. The first issue to be clarified is sign languages used by hearing people. It is widely explained that how hearing people use their sign languages which are different from Deaf communities' sign languages. Next, existing languages are discussed and it is said that there are 6.703 languages according to Ethnologue database (Ethnologue database 1996). Mutual intelligibility and problems of nomenclature are the next stated subtopics. Mutual intelligibility is stated to be an important issue because two nations' languages may be very similar; however, they may be accepted two different languages (ex. Swedish and Danish, New Zealand Sign Language and Australian Sign Language). Afterwards, naming sign languages in Europe is defined, which states according to European Union of the Deaf's study, sign languages' names are defined by the specific region of the country (Belgium, Spanish sign languages, etc.). Another issue discussed in this chapter is historical relationships of languages. In spoken languages family trees of languages may show the origins of the languages; however, sign languages may not be divided into families; only some patterns and relationships may be defined. Lastly the issue how world politics and educational systems affect sign languages is discussed.

\footnotetext{
${ }^{1}$ Çanakkale Onsekiz Mart University, Faculty of Education, ELT Department, MA. E-mail: ebrualtin@gmail.com
} 
The second chapter discussed by Ann is bilingualism and language contact. The first topic to be discussed in this chapter is societal and individual bilingualism in the hearing world. Giving examples from Canada, Belgium and Singapore she states that although the society has bilingual policy, many of its speakers may be monolingual. In terms of deaf world, examples from three villages in USA, Mexico and Indonesia indicates that both hearing and deaf people signs and being deaf is a normal phenomenon. Discussion goes on with the issue that bilingualism in the deaf world and it is clearly explained whether deaf community may be bilingual or not. The term diglossia is the next issue to be examined. Diglossia in hearing world is widely explained; however, in deaf communities it is stated to be a controversial issue. Ann clarifies the influence of a first language upon the second language and she discuss the terms taking into consideration the sign languages. Moreover, she sheds light on loan vocabulary explaining it in two ways fingerspelling and character signs. In addition, she explains mouthing which is also connected to speech. Lastly, pidgins and creoles related to sign languages are discussed and code switching and code mixing are clarified.

Next chapter, sociolinguistic variations is written by Lucas, Bayley, Valli, Rose and Wulf. In this chapter, sociolinguistic variation on the spoken language and sign language are examined. They firstly represented the studies on spoken language and then states the studies on sign languages and at the end they compare the findings and criticize the lacking parts of the findings. Linguistic variation is discussed in depth explaining sociolinguistic variable, variable units in spoken language like phonology, syntax, etc. Different studies on linguistic variation in spoken languages are examined. As a next step, the main aim of the chapter which is linguistic variation in sign languages is discussed and stating that variation in sign languages are also available by the help of many studies' findings they clarify these variations. Afterwards, sign languages and spoken languages are compared in terms of variable units, variable process, internal constraints and social constraints. At the end of the chapter, three studies on variation in sign languages are reviewed and in the studies the changing perspectives on sign language structure and use are defined. The main point of the chapter is variations in both spoken and written languages are systematic and although the social factors such as region, gender, age, etc. are the same for both languages, some factors such as language use at home is unique to sign language variation.

In the $4^{\text {th }}$ chapter, Metzger and Bahan discuss the discourse analysis in both spoken and sign languages. They start with examining the discourse structure and discourse interaction in spoken languages. Moreover, after they add the relations of discourse and context, they explain the methodological approaches to discourse analysis which are speech act theory, interactional sociolinguistics, ethnography of communication, pragmatics, conversation analysis and variation analysis. These approaches are related with sign languages and examined in terms of sign languages since they have also been applied to the study of sign languages discourse. Afterwards, the features of sign language discourse are stated in depth. The first feature which is turntaking in sign languages is described with examples and the unique features to sign languages are stated. Next, conversational repair and occurrence of false starts are discussed stating that nonhanded signs such as brief handshake and head movement to the right then left and lastly in normal position may be used to repair. Later, discourse markers such as 'and, but' and using such markers while signing is described. The ways of constructing dialogue and acting out is discussed as a next step and making them coherent is questioned. Lastly, some of the strategies to involve addressees more in what is being uttered is discussed under the terms of rhythm, rhyme and repetition. At the end of the chapter, the relevance of discourse genre is stated in terms of weather being monologic or dialogic and taking into consideration the approaches stated above.

Reagon intends to show the importance of language planning and policy in the $5^{\text {th }}$ chapter. He starts with the description of language planning and policy which mean creating new terminology where needed and then explains the nature and purposes of language planning and language policy activities in general. He states that language planning activities occurring both in status planning and corpus planning serve five different functions which are language purification, language revitalization, language reform, language standardization and language modernization. He explains each function in terms of both spoken languages and sign languages. Next topic being discussed is the role of ideology 
in language policy. Here, four ideologies of language policy which are linguistic assimilation, linguistic pluralism, vernacularization and internationalization are discussed. It is stated that ideologies play important roles in both status and corpus planning for sign languages and spoken languages. Afterwards, the language planning process is explained in three stages which are gathering information, determining of goals, strategies and outcomes and evaluating. The last stage is stated to be the most neglected but the most important stage. Next, issues of language rights in language policy debates and the use of language planning and language policy to achieve social, political and educational ends are discussed. It is stated that these policies may be misused as to maintain social class discriminating and social and educational discrimination. At the end of the chapter, evaluating language policies is discussed deeply. As a conclusion, it is indicated that language planning activities may be done with sincere efforts; however, they may fail to take into consideration the complex language rights of deaf and hearing people.

In the sixth part language attitudes are discussed by Burns, Matthews and Nolan-Conroy. The chapter starts with questioning why language attitudes are studied and provides some definitions of the term according to mentalists and behaviorists. Here the term explained in terms of both sign languages and spoken languages. Later, some of the early research after 1960s is examined and which languages have been seen superior to which ones in both spoken and sing languages are defined. Moving to the next topic, how language attitudes studies have been carried out is discussed. As an explanation to this question it is said that language attitude measurement techniques have been divided into three categories which are content analysis, direct measurement and indirect measurement. Related to the studies, some of the questions addressed, some of the answers are given and theories were developed related to the questions. In the following issues which are attitudes toward languages and language groups, it is stated that while majority language is generally regarded as superior and people have positive attitudes toward them, minority language is viewed negatively. This is the case for the deaf community, it is thought that sign languages are inferior and deaf community is in the same opinion as well. Towards the end of the chapter, consequences and applications are discussed in the light of three fields which are positive or negative attitudes toward second language, employee's hiring practices which is generally negative toward minority groups, unsuccessfulness of mass media and the most important field in terms of influence of attitudes on it which is education. At the end of the chapter, it is stated that attitudes change over time and are never stable. Additionally here, it is indicated that languages or language groups which were accepted as inferior may become accepted and respected.

As bringing together many researchers' ideas under six main topics of sociolinguistics and indicating all the issues' relevance to sign languages, Lucas collects a number of valuable and informative ideas together. In each chapter, the topics are discussed in terms of spoken languages and then they are discussed in terms of sign languages in depth. In each chapter, many studies, their findings and some implications or reflections are provided. The topics are presented from specific fields to broader social fields which makes the cohesion of the ideas easier. Since all the ideas in the chapters are supported by a great number of studies, it is worth reading to have a wide general knowledge on the issues. The organizations of the chapters are well designed, thus it does not cause readers to miss the path and get lost. On the contrary, it is easy to follow the ideas the writers want to convey. Starting each chapter, with quotations not only give a general overview of the chapter, but also arise readers' curiosity on the matter of issues mentioned in the chapters.

On the other hand, some chapters include unnecessary definitions and explanations on spoken language fields. Since this is a book dealing with the sociolinguistics of sign languages, it would be profitable to analyze the sign languages in depth. While the most informative and useful chapters are multilingualism, bilingualism, discourse analysis and language attitudes; the less preferable topics are sociolinguistic variation and language planning and policy. The topic sociolinguistic variation is less comprehensible in terms of sign languages since some of the readers may not be familiar with the normal fingerspelling or mouthing of sign languages. In language planning and policy chapter the terms used to explain the issues are based on terminology and are vague. 
All in all, Ceil Lucas provides a practical way to understand the sociolinguistics of sign languages. Her book sheds light on the social and linguistic perspectives of sign languages. The Sociolinguistics of Sign Languages is highly recommended to all people who are interested in sign languages and want to build their own philosophy on sign languages sociolinguistics.

\section{References:}

Lucas, C. (2004). The Sociolinguistics of Sign Languages. UK, Cambridge: Cambridge University Press. 